\title{
A Statistical Analysis for Increasing Reward with Increasing Size of Jam'at
}

\begin{abstract}
Ahmed F. Siddiqi
Abstract

The concept of jam'at is one of the most intrinsic concepts of the social edifice of Islam. The reward of a salaat, as enunciated by Holy Prophet (SAW) is multiplied by saying it in jama'at. There are sayings of the Holy Prophet (SAW) which can be made to show that the reward of a jama'at is a mathematical function of that of a salaat said individually. This paper is an attempt to find that function. It is being established here that this function is parabolic, with a very sharp slope in nature, and may be deduced to extrapolate the divine reward one may have by saying a salaat in jama'at, at one hand, and to appraise the increase in reward with the size of the jama'at. The same function also connects different, apparently conflicting sayings of the Holy Prophet (SAW) regarding the comparisons in this reward.
\end{abstract}

Keywords: Least Square, Reward for Salaa

\section{Introduction}

The concept of jam'at, congregation, is one of the basic and the most cited concepts in Islam. The Holy Quran ordains "...bow down your heads with those who bow down..." ${ }^{1}$. The essential part of every obligatory prayer, salaat, called fardh, are said in jama'at. The whole Muslim body that can assemble in one place, both men and women, must gather at the appointed time, praise and glorify God, and address their petitions to Him as a single body. All people stand shoulder to shoulder in a row, or in several rows, as the case may be, their feet being in one line, and one person, chosen from among them, and called Imam, leads the salaat, and stands in front of all. Such a formation develops a unique social cohesiveness among the members of this formation. And perhaps, this social cohesiveness is the most important earthly reward of this jam'at which promotes connectedness in the community.

The salaat is one of the most important duties of a Muslim, after one has reached faith in one God and in Prophet Mohammad $(S A W)$. It is the most special act of divine worship, which a Muslim is called upon to practice five times a day. There are numerous verses of the Holy Quran and the Traditions of the Prophet $(S A W)$ enjoining the salaat on us. It has been described as the pillar and the foundation of the faith. Salaat, if offered with a sincere heart, proper devotion and mental concentration, is particularly vested with the property of cleansing the heart, reforming one's life and ridding it of sins and impurities. It generates love for piety and truth and promotes fear of God in man. It is further ordained that the bounties of salaat are multiplied when said in $j a-$ $m a$ 'at. The Holy Quran has clear verdict on the jama'at. The Prophet $(S A W)$ was very particular about it; once while condemning the conduct of Muslims those who avoided coming to the mosque to say their prayers in jama'at due to laziness or indifference, he observed with anger that he felt like burning down their homes.

There are several traditions in which the Prophet of Islam, Mohammad $(S A W)$, dilated upon the value and rewards of salaat, especially salaat said in jama'at from different dimensions. Followings are a few of these holy sayings of the Prophet $(S A W)$ comparing the reward of a salaat said individually and in jam'at;

1. Saying salaat in jam'at is better than saying individually. Jam'at of three is better than that of two and the liking of Allah increases with the size of jam'at. ${ }^{2}$

2. Two persons performing salaat together, with one as imaam, are liked by Allah more than four persons saying salaat individually; similarly, four persons performing salaat with jama'at (congregation) are liked by Allah more than eight persons saying it individually and (again) eight persons performing $s a$ laat with jama'at are liked by Allah more than one hundred persons saying it individually. ${ }^{3}$

3. Saying salaat in jam'at is 25 times more reward giving as compared to a salaat said individually in home and/or market place. ${ }^{4}$

4. Salaat in jam'at is 27 times more reward giving as compared to that in individual. ${ }^{5}$

All these holy sayings, bullet 1 to 4 , show numerical comparisons between the salaats said individually and in jama'at. The holy saying in bullet 1 show the liking of Allah for a jama'at as increased by increasing the size of jama'at from two persons to three. But it does not quantify the increase in this liking. The saying in bullet 2 discusses the value of reward, as a proxy of Allah's liking. It does quantify and show the details of the 
arithmetic for the value of reward as increased with the size of the jama'at. The sayings in bullet 3 and 4 are again a comparison of the reward but without the details and seem to be in conflict with what is being said in bullet 2 and even in bullet 1 . The conflict as it appears, or the difference in the numerals is quite perplexing, especially for staunch believers who cannot even think of any difference in the holy sayings. The religious literature of Muslim is silent in this regard. No academic research is available either. Qurashi ${ }^{6}$ opines however, that it is related, or specific, to higher sizes of the jama'at while discussing these sayings in the study of motivation.

Let's explore the arithmetic given in holy saying in bullet 2 . In tabular form, the arithmetic is given in Table 1.

Table 1: The Value of Reward as Increased by the Size of the Jam'at

\begin{tabular}{|l|l|l|l|l|}
\hline Persons in Jam'at & 1 & 2 & 4 & 8 \\
\hline Total & 1 & more than & more than & more than \\
\hline Reward & & 4 & 8 & 100 \\
\hline Reward for Each & 1 & $\begin{array}{l}\text { more than } \\
\text { Individual }\end{array}$ & $\begin{array}{l}\text { more than } \\
8 / 4=2\end{array}$ & $\begin{array}{l}\text { more than } \\
100 / 8=12.5\end{array}$ \\
\hline
\end{tabular}

The ratios in the last rows are not part of the holy saying and are deduced by dividing the total rewards by the number of participants of the jama'at. A graphical depiction of these statistics is given in Figure 1; where 1(a) in left panel shows the dynamics of the total reward of the salaat as the number of participants grow, while 1(b) gives the dynamics of the reward for each participant of the salaat. The value of the reward, in both cases, increases very sharply as the size of the jam'at grows. One may be curious to find the value of reward for other numbers of participants. The current article is an attempt in the same direction. It should be noted here that the attempt is mere by a mathematical deduction of the holy saying and not in any way an inductive interpretation. It is simply an effort to extrapolate the value and amount of reward for other higher sizes of the jama'at.

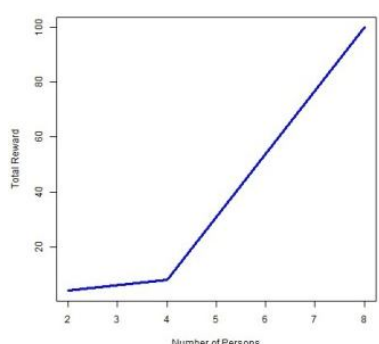

(a) Total Reward

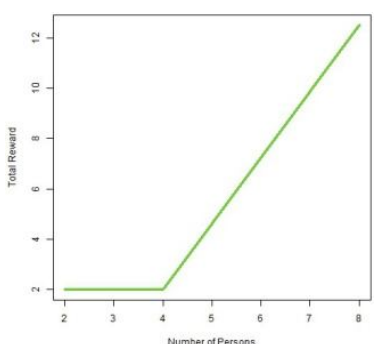

(b) Individual's Reward
So, the reward of the salaat in jama'at (congregation) is proportional to the reward of the salaat said individually. Mathematically, this proportionality may be written in the form of a function;

Reward of jam'at $=\mathrm{f}$ (Reward of Individual salaat) (1)

The form and the shape of this function $f$ is interesting enough to forecast the value of reward for the whole jama'at and for the individual. The following sections suggests different approaches to mimic, in the first hand, the curve in the form of a mathematical function which may further be used to extrapolate, or forecast, the value of reward for any number of participants of the jam'at.

\section{Exploring the Mathematical Function}

The saying of Holy Prophet ( $S A W$ ) may be deduced into a value of total reward for the jama'at when the size of the jama'at increases continuously. Similarly, the value of the reward for each individual person in the jama'at may also be deduced.

Let's use the principle of least squares ${ }^{7}$ to fit an appropriate curve to the data which may be used to extrapolate or forecast the value of reward for any number of persons. Figure 1(a) suggests it either to be a parabolic, power or an exponential curve (and absolutely not linear) which may well represent the data. Figure 2 gives few choices for the possible curves for the data including power, parabolic and exponential curve. Figure 2 (a) is a power curve for the data in the Hadith. It appears to miss two data points which obliterate its representativeness. Figure 2(b) is a parabola and uses all the data points. The right most panel, Figure 2(c), shows an exponential curve which is also missing the last data point and which results in its lesser representativeness. Qurashi (1983) uses a power curve to derive formula for motivation, cooperation and achievement of a team. The parabolic curve, Fig. 2(b) seems to be more representative for the data.

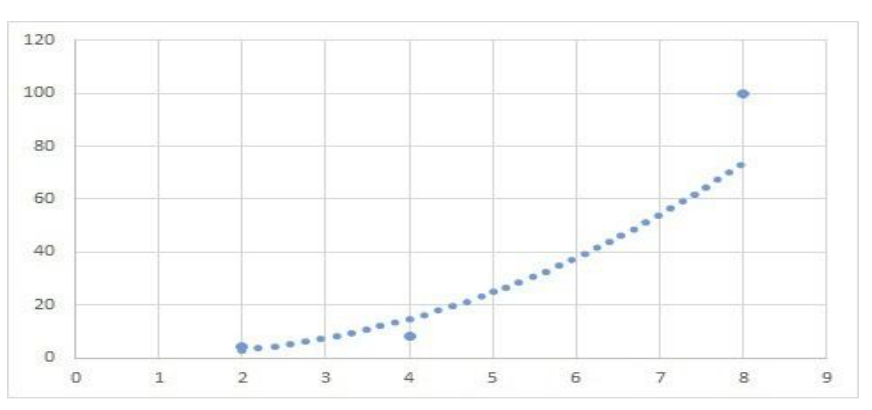

(a) Power Curve

Figure 1: Graphical Depiction of the Hadith 


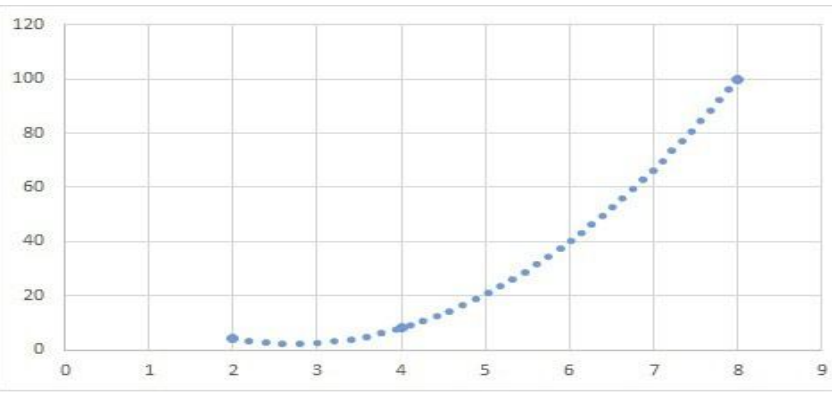

(b) Parabolic Curve

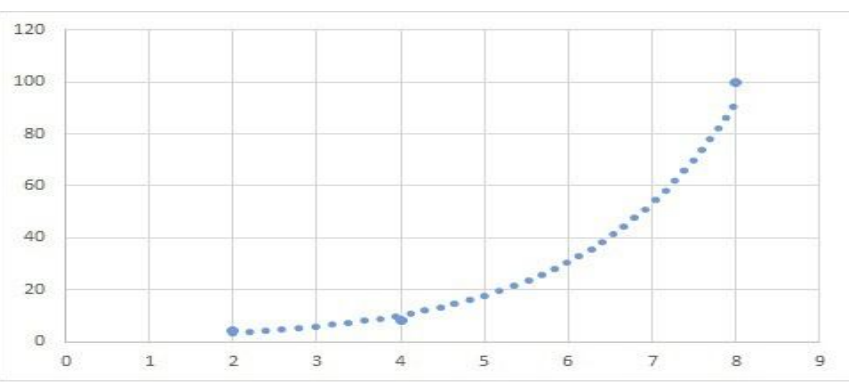

(c) Exponential

Figure 2: Possible Curve Choices for the Data

Symbolizing the individualistic reward of each persons by $p$ (with $p>0$ ) and the value of reward (in terms of this individualistic reward) by $r$, the data can be composed into Table 2 for the application of the principle of least squares; The first two columns are simply a re-written form of the saying as columns in Table 1 while the rest of the columns are different products of these columns, as per the principles, to be used for the composition of normal equations.

The three normal equations are thus given by:

Table 2: Fitting a Parabola by Using Principle of Least

\begin{tabular}{ccc|ccccc}
\hline & $\mathrm{P}$ & $\mathrm{R}$ & $\mathrm{PR}$ & $\mathrm{P}^{2}$ & $\mathrm{P}^{2} \mathrm{R}$ & $\mathrm{P}^{3}$ & $\mathrm{P}^{4}$ \\
\hline 2 & 4 & 8 & 14 & 16 & 8 & 16 \\
4 & 8 & 32 & 16 & 128 & 64 & 256 \\
& 8 & 100 & 800 & 64 & 6400 & 512 & 4096 \\
\hline Sum & 14 & 112 & 840 & 84 & 6544 & 584 & 4368 \\
\hline
\end{tabular}

$$
\begin{aligned}
& 112=3 a+14 b+54 c \\
& 840=14 a+84 b+584 c \\
& 6544=84 a+584 b+4368 c
\end{aligned}
$$

Solving these equations for the unknowns a, b, and c, using the method of matrices,

$$
\begin{gathered}
\left(\begin{array}{l}
a \\
b \\
c
\end{array}\right)=\left(\begin{array}{ccc}
3 & 14 & 84 \\
14 & 84 & 584 \\
84 & 584 & 4368
\end{array}\right)^{-1}\left(\begin{array}{c}
112 \\
840 \\
6544
\end{array}\right) \\
=\left(\begin{array}{c}
28 \\
-19 \\
3.5
\end{array}\right)
\end{gathered}
$$

So the parabolic equation, or the functional form of Eq. 1 , turns out to be

$$
r_{t}=3.5 p^{2}-19 p+28
$$

which shows that the reward of a salaat said in jama'at is exalted by a function, as defined in the right hand side of the Eq. 2. The same equation may also be used for extrapolation and forecasting. Table 3 shows the extrapolated values and how the size of the jam'at increases the value of the reward of the whole salaat. The first column of the table shows the size of the jam'at in terms of number of its participants while the second column shows the value of the reward in terms of individuals saying their salaat individually. For example, the reward of a jama'at said by 10 persons is more than $3.5 \times 10^{2}-19 \times 10+28=188$ times that of a salaat said by a single person. Similarly, the reward of the jama'at said by 100 persons is increased by 33,128 times than that said by a single person. The reward goes up exponentially.

Table 3: Extrapolated Values of the Reward

\begin{tabular}{lcr}
\hline Size of Jam'at & Total Reward & Individual's Reward \\
\hline 5 & 20.5 & 3.3 \\
10 & 188 & 23 \\
15 & 530.5 & 64.6 \\
20 & 1048 & 128 \\
25 & 1740.5 & 213.3 \\
30 & 2608 & 320.5 \\
40 & 4868 & 600.5 \\
50 & 7828 & 968 \\
100 & 33128 & 4118 \\
\hline
\end{tabular}

A similar analysis for the reward per person can also be deduced from the Holy saying. Figure 1(b) suggests again a parabolic curve for the data being the most representative curve mimicking the data in the holy saying. The method of least squares gives an equation for the value of reward per person.

The forecasting equation turns out to be

$$
r_{i}=0.4375 p^{2}-2.625 p+5.5
$$

which shows that the value of the reward per person is given by a function on the right hand side of the Eq. 3 . The same equation may also be used for forecasting. 
The last column of the Table 3 shows how this equation may be used for different sizes of the jama'at. For example, the individual reward of each person in a jama'at of 15 persons is more than $0.4375 \times 15^{2}-$ $2.625 \times 15+5.5 \approx 65$ times than that of a salaat said singularly.

The same table seems to be solving the confusion which arouses while reading holy sayings, in bullets 1 through 4 , one after the other. The saying in bullet 2 goes up to 8 persons while the value of individual reward of each person in a jama'at of 10 persons is deduced to be more than 23 times that of a salat said singularly, as per column 2 of Table 3. And this is very near to what is being said in the sayings at bullet 3 and 4 . So, there is no confusion in these sayings as bullet 2 talks in terms of total reward of the jama'at while the later two sayings talk in terms of individual's reward. In other words, the sayings at bullet 3 or 4 is/are a continuation of the saying in bullet 2 .

A general view of these equations is shown in Figure 3, which is a graphical presentation of these two equations, Eq. 2 and 3, and shows how the holy saying in bullet 2 can be deduced to extrapolate the value of reward for different sizes of the jama'at. The left panel, 3(a), shows the extrapolation of the total reward with the size of jama'at while the right panel, 3(b), shows this extrapolation for the value of reward for each individual participant of the jama'at. An exponential curve with a very sharp slope is the characteristic feature of both of these figures which shows how rapidly the reward of a jama'at increases with the size of this $j a$ ma'at.

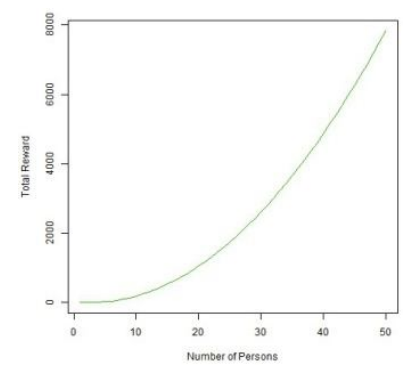

(a) Total Reward

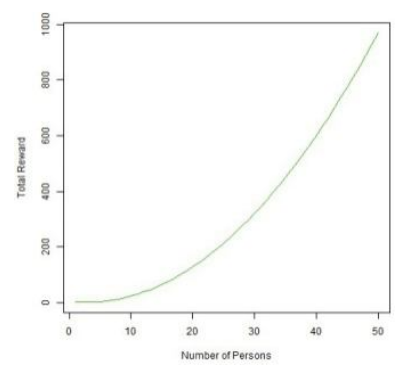

(b) Individual's Reward
Figure 3: Forecasted Reward for Jam'at

\section{Conclusion}

The concept of jama'at is among the most important concepts in Islam. It has been ordained, in the Holy Quran, to "bow down heads (for salaat) with those who bow down." There have been many traditions and sayings of Holy Prophet $(S A W)$ exalting the status of the salaat said in jama'at, in terms of its divine reward. Further, it has been told (by Holy Prophet $(S A W)$ ) that the reward increases with the size of jama'at. However, these sayings portray apparently only a fragmented figure, especially when one wants to read them for the relationship between the value of reward and the size of the jam'at. Further, different sayings seem to be at odds with each other. It has been attempted in this paper to make deductions and extrapolate the value of this divine reward and connect these, seemingly different and conflicting, sayings to complete the picture.

It has been derived here that the relationship between the reward of a salaat said in jama'at and the size of the jama'at is parabolic, as narrated by the Holy Prophet $(S A W)$, in nature. This parabolic function can thus be used to deduce and extrapolate the value of reward for different sizes of the jama'at. The same parabolic function connects different apparently conflicting sayings of the Holy Prophet $(S A W)$

It should be kept here in the mind that the analysis presented here is simply a deduction of the saying of the Holy Prophet $(S A W)$ and the actual reward of the $s a$ laat, either said singularly or in congregation, is known only to Allah, (SWT), who may exalt the reward many times higher than the figures deduced here.

\section{References and End Notes}

${ }^{1}$ Quran, 02:243; And be steadfast in prayer; Practise regular charity; a nd bow down your heads with those who bow down (in worship).

${ }^{2}$ Imam Abu Dawood Sulaiman b Ash'ath, Sunan Abi Dawood, chapter 02, "Prayer" Hadith numb, 2554.

${ }^{3}$ Ahmad bin "Amr al Bazzar and Sulaiman b Ahmad al Tabrani , Musnad of Imam Bazzar and Tabarani, 1352; Ali ibn Abu Bakr al-Haythami, Majma al-Zawa'id, Mu'assasah al-Ma' arif, Beirut

${ }^{4}$ Muhammad bin Ismail al Bukhari, Sahih Bukhari, 8466.

${ }^{5}$ Muslim ibn-e-Hajjaj, Sahih Muslim, 1477.

${ }^{6}$ M. Qurashi, "A Statistical Analysis of Motivation, Cooperation \& achievement- part iv Formula for increase of value/reward with increasing size of jama'at/congregation, vis-a-vis mutual interaction". Science \& Technology in the Islamic World, vol 1, no. 4 (1983):227235.

${ }^{7}$ Plackett, R. L. "Studies in the History of Probability and Statistics. Xxix: The Discovery of the Method of Least Squares. Biometrika, vol.59, no,02 (1972): 239-251. 


\section{Selected Bibliography}

al-Bazzar and Tabarani, Musnad of Abu Bakr al-Bazzar and Al-Tabarani. $1352 \mathrm{AH}$.

al Haythmi, Ali ibn Abu Bakr. Majma al-Zawa'id. Mu'assash al-Ma'arif, Beirut.

Bukhari, M. Sahih al-Bukhari. Dar al-Fikr. 466A.H. Abu Dawud, Sulaiman b Ash'ath. Sunun Abu Dawud, Dar alFikr.

Muslim, Ibn-e-Hajjaj. Sahih al-Muslim,. Dar al-Fikr. Plackett, R. L. "Studies in the History of Probability and Statistics. Xxix: The Discovery of the Method of Least Squares. Biometrika, vol.59, no,02 (1972): 239-251.

The Meaning of The Holy Quran by Abdullah Yusuf Ali. Amana Corporation, Maryland, USA.

Qurashi, M. "A statistical analysis of motivation, cooperation \& achievement- part iv formula for increase of value/reward with increasing size of jama'at/congregation, visa-vis mutual interaction". Science \& Technology in the Islamic World, vol 1, no. 4 (1983):227-235. 